\title{
MUSEUM ARSITEKTUR JAKARTA DI KAWASAN MEDAN MERDEKA TIMUR
}

\author{
Nicholas $^{1}$, Maria Veronica Gandha ${ }^{21}$ \\ 1)Program Studi S1 Arsitektur, Fakultas Teknik, Universitas Tarumanagara, t.nicholasantoso@gmail.com \\ 2) Program Studi S1 Arsitektur, Fakultas Teknik, Universitas Tarumanagara, mariag@ft.untar.ac.id
}

\begin{abstract}
Abstrak
Seiring berjalanya waktu, Museum di kota Jakarta masih tetap terbatas. Karya karya yang dipamerkan tetap sama dan cenderung tidak interaktif. Kebanyakan museum di Jakarta mencoba menampilkan sisi historis dari penjajahan Belanda dan peninggalannya. namun belum ada museum yang membahas bagaimana arsitektur di kota Jakarta berkembang pesat sampai sekarang dan meninggalkan cerita atau sejarahnya. Dalam paparan sejarah pertumbuhannya, dimana pemerintah kotanya silih berganti dan kondisi masyarakatnya sangat majemuk. Namun dalam perjalanannya menuju era yang lebih modern, perlu adanya sebuah perubahan terhadap konsep museum. Menurunya angka kunjungan ke museum harus menjadi perhatian bahwasanya generasi milenial mulai meninggalkan tren berwisata ke museum karena museum dinilai terlalu tua dan tidak berkembang. Hadirnya museum arsitektur Jakarta bercerita gambaran perjalanan arsitektur kota Jakarta yang berkembang sejak zaman penjajahan Belanda hingga saat ini. Perancangan Museum yang terletak di kawasan Merdeka Timur berbatasan langsung dengan bangunan tua yang memiliki nilai sejarah, Gereja Immannuel dan Galeri Nasional; Selain itu kawasan ini terhubung dalam satu jalur pariwisata yang sedang di kembangkan, dari Masjid Istiqlal dan Gereja katedral (yang mana memiliki nilai historis arsitektur) hingga Tugu Proklamasi di jalan Proklamasi. Dengan adanya satu hubungan lingkage antar dua titik tujuan. Proyek ini juga berinteraksi dengan sekitarnya sebagai tempat yang nyaman dengan ruang terbuka untuk masyarakat sekitar. Program kemduian didukung dengan ruang 3.0 yang berupa amphiteather, dimana dapat di akses oleh berbagai kalangan baik secara kelas horizontal maupun vertikal. Proyek ini diharapkan dapat menambah wawasan maupun minat pengunjung untuk mempelajari arsitektur dan peranannya dalam membangun kota.
\end{abstract}

Kata kunci: arsitektur; jakarta; kota; milenial; sejarah

\begin{abstract}
As time went on, the Museum in the city of Jakarta was still limited. The works exhibited remain the same and tend not to be interactive. Most museums in Jakarta try to show the historical side of Dutch colonialism and their heritage. but there is no museum that discusses how architecture in the city of Jakarta has developed rapidly until now and left its story or history. In the historical exposures of its growth, where the city government alternates and the conditions of its society are very diverse. But in its journey to a more modern era, there needs to be a change to the concept of the museum. The decline in the number of visits to the museum should be a concern that the millennial generation has begun to abandon the trend of traveling to museums because the museum is considered too old and undeveloped. The presence of the Jakarta architecture museum tells the story of the architectural journey of the city of Jakarta which has developed since the Dutch colonial era to the present. The design of the Museum which is located in the East Merdeka area is directly adjacent to the old building which has historical value, the Immannuel Church and the National Gallery; In addition, this region is connected in one tourism path that is being developed, from the Istiqlal Mosque and the Cathedral Church (which has historical architectural value) to the Proclamation Monument on the Proclamation Road. With a relationship between two destination points. The project also interacts with its surroundings as a comfortable place with open space for the surrounding community. The general program is supported by space 3.0 in the form of amphitheater, which can be accessed by various groups both horizontally and vertically. This project is expected to increase the insight and interest of visitors to study architecture and its role in building cities.
\end{abstract}

Keywords: architecture; city; history; jakarta; millennial 


\section{PENDAHULUAN}

Jakarta merupakan salah satu kota metropolitan di Indonesia yang banyak kegiatan terjadi seperti perekonomian, perdagangan, pariwisata, dan lain-lain. Berbagai macam kegiatan yang telah disebutkan diatas menjadi salah satu faktor yang dapat memberikan keuntungan bagi sektor perekonomian, salah satunya adalah sektor pariwisata. Kawasan Medan Merdeka, merupakan Kawasan pemerintahan Republik Indonesia, yang saat ini dalam tahap pengembangan pariwisata. Gubernur DKI Jakarta 2017-2022 Anies baswedan, menyatakan pada dasarnya kota Jakarta sedang menuju smart city 4.0, yang mana kota Jakarta kedepanya harus mewadahi dan terus berkembang menjembatani kehidupan masyarakat milenial yang mulai menempati piramida penduduk terbesar.

Berbicara tantang generasi milenial, milenial ternyata identik dengan generasi yang sangat akrab dengan gadget. Saluran informasi tersebar luas dengan bantuan internet, media pembelajaran jauh lebih mudah. Mempelajari suatu hal tidak melulu harus melihat langsung, dan berselancar di dunia maya menjadi jawaban. Dengan latar belakang gawai dan internet yang besar, kesadaran anak terhadap suatu nilai historis dari segi filosofis dan objek itu sendiri menjadi hilang. Terlebih ketika orang tua lupa mengajak atau mengenalkan museum ke anaknya sejak dini.

Museum masih dianggap sesuatu yang kuno, kaku, angker, dan tidak menarik. Padahal generasi milenial identik dengan sesuatu yang sifatnya dinamis, praktis atau serba cepat. Tidak seperti halnya di negara-negara yang literasi masyarakatnya memadai. Museum sudah menjadi bagian tempat dalam meningkatkan literasi. Mengunjungi museum sudah menjadi gaya hidup bagi mereka. Tetapi masyarakat Indonesia belum memiliki pandangan tersebut. Harus ada perubahan pola dalam pengelolaan museum. Para pengelola museum di Indonesia harus menyadari ini.

Bahwa harus ada perubahan paradigma dalam pengelolaan museum. Pengelolaan museum harus dengan manajemen profesional. Pengelolaan yang profesional tidak saja dalam tampilan fisik seperti penempatan benda koleksi, etalase yang menarik, atau pun tampilan gedungnya dengan dilengkapi cafè. Tetapi tetapi juga dalam hal manajemen pengelolaan pelanggan atau pemasaran. Manajemen pengelolaan pengunjung harus dengan penanganan yang profesional tidak sekedar orang datang terus tidak ada tindak lanjut. Pengelola museum harus terus berbenah dan berinovasi agar pandangan masyarakat terhadap museum berubah. Pengunjung museum memang bertambah setiap tahunya mulai dari tahun 2010 (bps.go.id, 2019).

Proyek yang diusulkan adalah Museum yang berfungsi sebagai media pengembangan pariwisata yang sedang dikembangkan di Kawasan Medan Merdeka sekaligus membahas perkotaan Jakarta dan termasuk perkembangannya dari masa pra penjajahan hingga yang akan datang. Tak hanya itu museum ini juga ditujukan untuk pusat dokumentasi, informasi dan penelitian arsitektur DKI Jakarta. Dengan fungsi mengawetkan dan memelihara karya arsitektur di DKI Jakarta; Media pendidikan arsitektur DKI Jakarta, dengan fungsi utama untuk mendokumentasikan seluruh bangunan tua atau situs warisan dunia; Pusat apresiasi dan pengenalan serta pelestarian terhadap kekayaan arsitektur Jakarta; Sebagai cermin perkembangan arsitektur di Jakarta dari jaman pra-sejarah hingga masa kini, serta gambaran kemungkinan arsitektur di masa yang akan datang.

\section{KAJIAN LITERATUR}

\section{Museum}

Secara Etimologi kata museum berasal dari bahasa latin yaitu "museum" ("musea"). Aslinya dari bahasa Yunani mouseion yang merupakan kuil yang dipersembahkan untuk Muses (dewa seni dalam mitologi Yunani), dan merupakan bangunan tempat pendidikan dan kesenian, khususnya institut untuk filosofi dan penelitian pada perpustakaan di Alexandria yang didirikan 
oleh Ptolomy I Soter 280 SM. Museum menurut International Council of Museums (ICOM) adalah sebuah lembaga yang bersifat tetap, tidak mencari keuntungan, melayani masyarakat dan perkembangannya, terbuka untuk umum, memperoleh, merawat, menghubungkan dan memamerkan artefak-artefak jatidiri manusia dan lingkungannya untuk tujuan tujuan studi, pendidikan dan rekreasi. Sedangkan menurut peraturan pemerintah No.19 tahun 1995 pasal 1 ayat 1 adalah lembaga, tempat penyimpanan, perawatan, pengamanan dan pemanfaatan benda benda bukti materil hasil budaya manusia serta alam lingkungannnya guna menunjang upaya perlindungan dan pelestarian kekayaan budaya bangsa.

\section{Linkage}

Linkage adalah garis semu yang menghubungkan satu elemen dengan elemen lainnya, nodes dengan nodes lainnya, atau distrik dengan distrik lainnya. Garis ini bisa berupa jaringan jalan, jalur pedestrian, ruang terbuka, dan lain-lain. Teori linkage melibatkan pengorganisasian garis penghubung yang menghubungkan bagian-bagian kota dan design "special datum" dari garis bangunan kepada ruang. Spacial datum dapat berupa site line, arah pergerakan, aksis maupun tepian bangunan. Dalam teori, linkage memperhatikan susunan dari hubungan bagian kota satu dengan kota lainnya. Sirkulasi merupakan penekanan dari teori linkage yang mempertegas hubungan-hubungan dan dinamika dari urban fabric.

Teori linkage merupakan bentukan kota tidak lepas dari adanya jaring- jaring sirkulasi (network circulation). Network yang ada dapat berupa jalan, jalur pedestrian, ruang terbuka yang berbentuk linier ataupun bentuk-bentuk yang secara fisik menjadi penghubung antar bagian kota/kawasan.

\section{Sejarah Arsitektur Jakarta}

Setelah Indonesia merdeka, di kawasan Merdeka Selatan sejak tahun 1960 dibangun gedung-gedung baru seperti gedung kedutaan Amerika dan Bank Indonesia di Jalan Thamrin. Soekarno lalu memerintahkan pendirian Monumen Nasional dengan bentuk kombinasi konsep lingga yoni dengan tinggi melebihi menara Eiffel. Konsep tersebut mengandung makan simbolik persatuan kekuatan dasar dualistik (Ibu Bapak) untuk bangsa Indonesia merdeka. Dalam mitologi kebudayaan Jawa yang di kenal dengan lautan sebagai Ibu Pertiwi dan gunung sebagai Bapaknya.

Selepas kemerdekaan dan ibukota kembali ke Jakarta (sempat pindah ke Yogyakarta), dibangunlah kota Kebayoran Baru. Dalam waktu relatif singkat, kota-kota luar ini menyatu dengan Jakarta Raya. Pada 1948 populasi Jakarta masih 1.740 .252 jiwa dan pada 1963 menjadi 3.100.000 dan terus meningkat. Sebuah gagasan pada tahun 1953 memproyeksikan luas kota menjadi $162 \mathrm{~km}$ persegi yang akan dibatasi oleh lingkaran jalan merangkap batas perluasan kota. Lalu kemudian sejak 1959 perkembangan Jakarta menjadi bagian dari politik mercusuar dimana Indnoesia dijadikan pusat The New Emerging Forces.

Uang hasil Rampasan Perang Jepang digunakan untuk membangun 3 proyek strategis nasional yaitu Denpasar Hotel di Pelabuhan Ratu, gedung toserba Sarinah, dan Wisma Nusantara. 3 bangunan ini bertujuan untuk tujuan promosi paiwisata Indonesia. Sarinah menjadi Departemen Store pertama di Indonesia yang menggunakan teknologi terbaru seperti pendingin ruangan dan tangga berjalan. sarinah akan diproyeksikan sebagai tempat untuk memamerkan produk hasil industri dan kerajinan khas indonesia.

Untuk menyambut Asian Games IV dan GANEFO Bung Karno mencanangkan pendirian kompleks olahraga Senayan dengan pusatnya yaitu Gelora Bung Karno yang sebelumnya bernama Gelora Senayan. Dalam perencanaan rancangan Stadion Utama GBK, Soekarno ingin menyamai konsep kemegahan, kekokohan struktur serta artistik dari Stadion Lenin (Moskow). Tak hanya itu, Soekarno juga membangun mall Sarinah yang kemudian di tahun 1990 berkembang mall mall di Jakarta, seperti Mall Taman Anggrek, Plaza Senayan, Mall Puri Indah. Perkembangan mall kemudian menjadi tren pusat belanja di kota sebesar Jakarta. Semenjak 
ordebaru juga berkembang pula kantor kantor besar yang menempati di jalan Sudirman.

\section{METODE}

Dalam proses penulisan Tugas Akhir ini, menggunakan metode pembahasan dengan 3 tahap yaitu:

a. Tahap pengumpulan data.

b. Pengumpulan data dilakukan dengan cara:

- Melakukan survey lapangan dan observasi.

- Melakukan studi pustaka.

- Melakukan studi literatur pada proyek sejenis.

c. Tahap analisa.

d. Metode yang dilakukan dalam melakukan analisa adalah:

- Induksi, yaitu menarik kesimpulan dari fakta yang ada.

- Komparasi, yaitu menganalisis melalui data yang sudah dikumpulkan melalui survey dan studi literatur.

e. Tahap sintesis.

f. Tahap ini merupakan tahap perumusan konsep, dari hasil analisa.

4. DISKUSI DAN HASIL

Pengenalan dan Analisis Kawasan

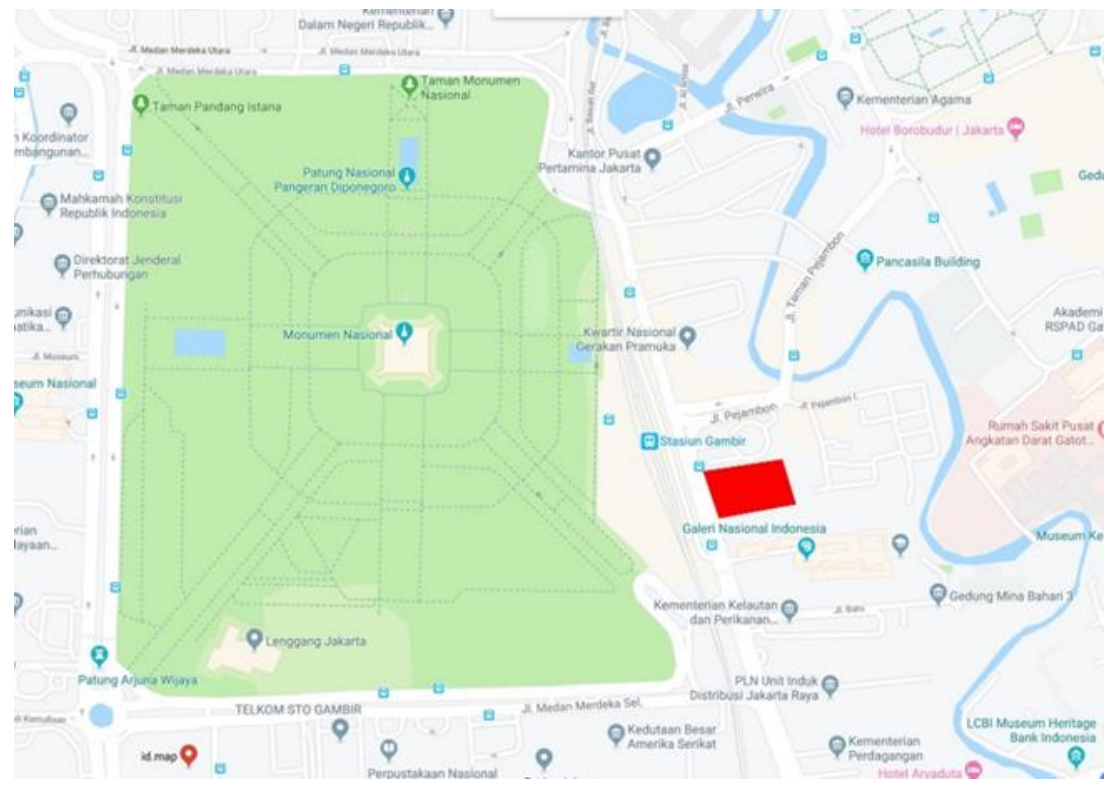

Gambar 1. Keberadaan Proyek terhadap Posisi kawasan Medan Merdeka atau Silang Monas Sumber: Google Earth dengan olahan pribadi 2019

Analisis tapak yang akan dipilih diawali dengan peninjauan langsung. yaitu dengan Survey pada daerah kawasan Medan Merdeka. Dari analisis tapak dengan mengunjungi langsung ke tapak, dilakukan pengamatan lingkungan dan lalu lintas sekitar, sehingga proses sintesa berjalan secara parallel dengan proses desain. Dengan posisi tapak yang menghadap barat, dan mengingat fungsi bangunan adalah museum maka perlu peninjauan tentang efek pembayangan dan panas yang di serap oleh bangunan. Oleh sebab itu dengan rentang masa pergerakan matahari, pembayangan jatuh lebih banyak di bagian selatan, dan matahari akan banyak bermain di sisi utara, mengingat kota Jakarta berada pada selatan garis khatulistiwa. 


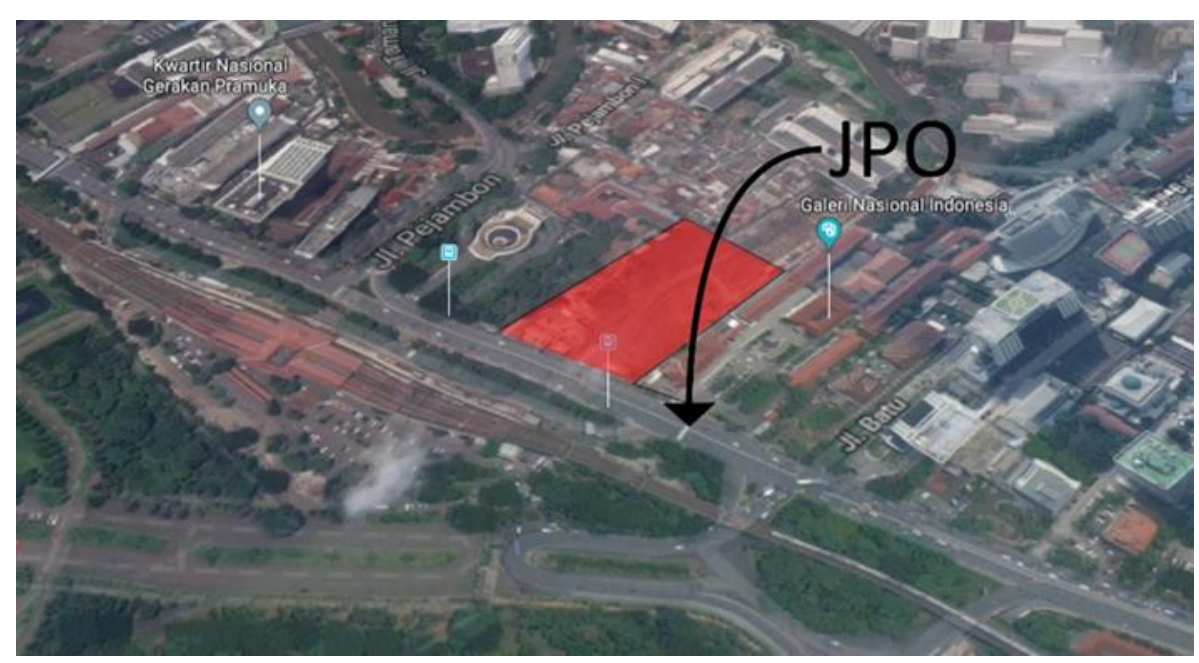

Gambar 2. Posisi Jpo sebagai askes utama pengunjung

Sumber: Penulis, 2019

Kemudian pada eksisting juga terdapat jembatan penyebarangan pada sisi sebelah kanan tapak. Dalam analisis, jembatan penyebrangan ini terhubung dengan halte busway Monas 1 , posisi halte berada pada nodes silang monas.

\section{Fasad}

Fasad pada bangunan sebelah kiri untuk menghormati bangunan peninggalan sejarah, Gereja Immanuel; di desain dengan menciptakan fasad yang sederhana dengan tonjolan jendela untuk observasi lingkungan sekitar, sehingga pengunjung yang berada di dalam gedung mampu melihat secara langsung sejarahnya.

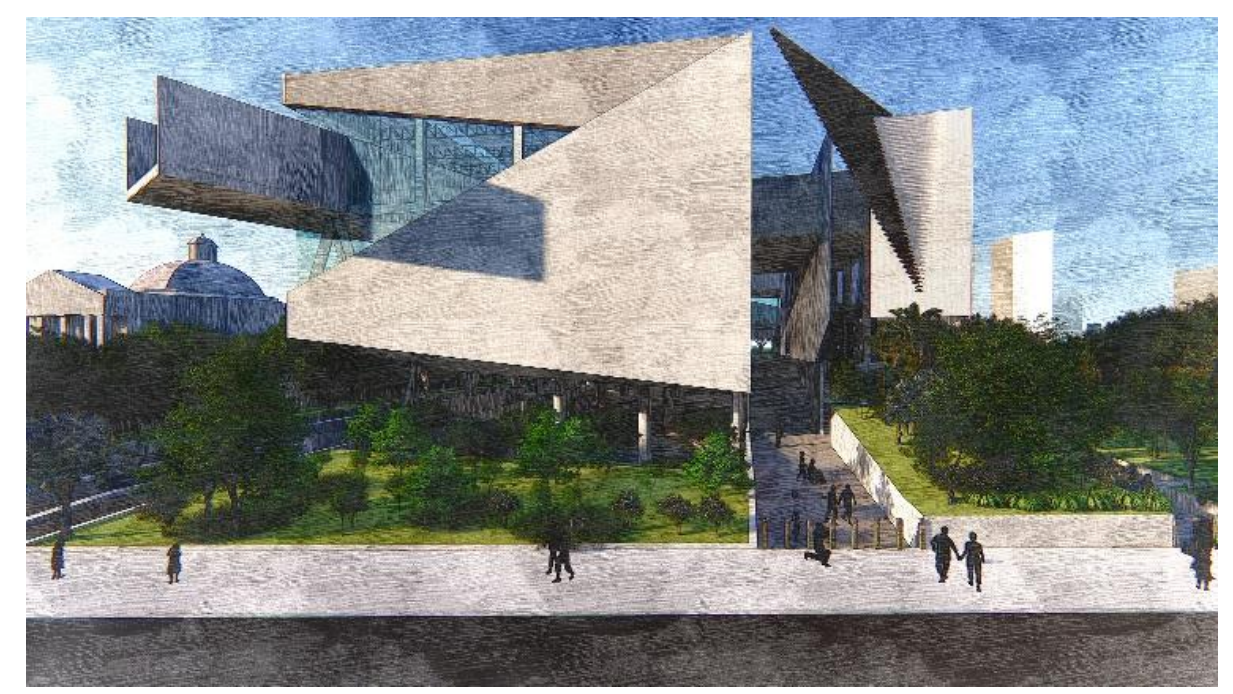

Gambar 3. Tampak Depan Museum Arsitektur sumber: Penulis, 2019

Pada fasad bagian sebelah kanan, karena berbatasan langsung dengan Galeri Nasional maka pada bagian sebelah kanan dibuat sebuah bukaan lebar dan view yang terbuka sehingga pada dasarnya menciptakan relasi yang relevan antara ruang di dalam museum dengan ruang luar termasuk dengan tetangganya.

Bagian depan bangunan kemudian di terjemahkan sekaligus menciptakan komposisi yang menarik, agar bangunan ini nantinya tidak terlihat besar sebelah, semuanya di harapkan proporsional. Kaca yang membuka secara lebar di sebelah kiri merupakan salah satu bentuk arahan agar dari dalam ruang terfokus pada perjuangan bangsa (Monas). 


\section{Denah dan Pembagian Ruang}

Untuk menciptakan ruang 3.0, museum sebenarnya diangkat setinggi enam meter dari muka jalan untuk memberikan ruang besar di bagian bawah yang di gunakan sebagai amphiteather. Dengan amphiteather yang di letakkan di bawah,pertama-tama diharapkan seluruh aspek dalam masyarakat mampu hadir tanpa adanya segregasi. Ruang 3.0 ini juga memiliki kelebihan diantaranya tidak menggunakan pengudaraan buatan, cahaya yang masuk teduh, suasanya dikelilingi oleh kerindangan pohon. Sebagai akses masuk utama kedalam museum, dibuatlah main entrance besar pada bagian kanan, sehingga pengunjung yang telah jalan langsung dari jembatan penyebrangan tidak terlalu jauh berjalan, hal ini mengacu pada batasan 250 meter maksimal jarak yang di tempuh oleh pejalan kaki.

Pada bagian main entrance, pengunjung langsung disambut dengan ruang pamer utama, dengan pameran temporer bernilai seni, hal ini dimaksudkan agar pameran ini masih relevan dengan Galeri Nasional yang berada di sebelahnya. Tak hanya itu harpanya juga untuk menciptakan kesan bahwa arsitektur juga bagian dari karya seni. Di ruang pameran temporer ini, pengunjung juga diarahkan langsung menuju pusat administrasi dan penitipan barang, baru kemudian pengunjung diajak untuk berkeliling menyelusuri ruang-ruang yang ada. Untuk sirkulasi pengunjung diarahkan untuk naik ke puncak bangunan, dimana pada bagian puncak bangunan terdapat pameran kota Jakarta di masa depan.

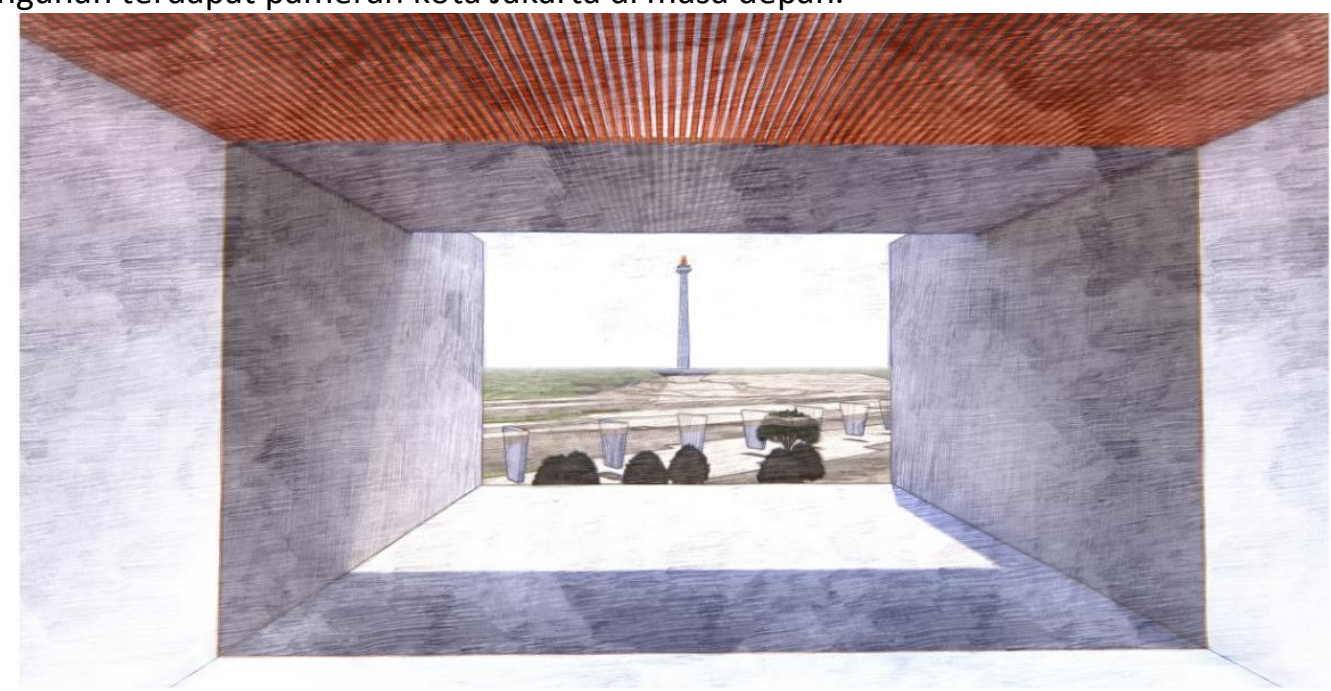

Gambar 3. Vista utama menuju Monas Sumber: Penulis, 2019

Dalam cerita yang ingin di sampaikan kepada pengunjung, jembatan besar yang mengarah ke arah monas merupakan bagian dari ruang pameran Proyek Mercusuar dimana puncak proyek tersebut adalah sebuah semangat untuk bangsa Indonesia. Perjalanan ruang digambarkan dengan sejarah sejarah proyek mercusuar dan ambisi bapak Proklamator. Pengunjung juga diajak untuk menikmati fenomena-fenomena yang ada di tiap lantainya. Dari jembatan atau cantilever mengarah pada Monas hingga jembatan gantung menuju lantai dua yang merepresentasikan cerita tentang pembangunan di Kota Jakarta ternyata menciptakan ruang ruang mati, yang di terkesan sempit akibat tingginya antar gedung bertingkat. Kesempitan dan lorong-lorong sempit kemudian diangkat agar pengunjung yang datang mengalami pengalaman ruang kesesakan. 


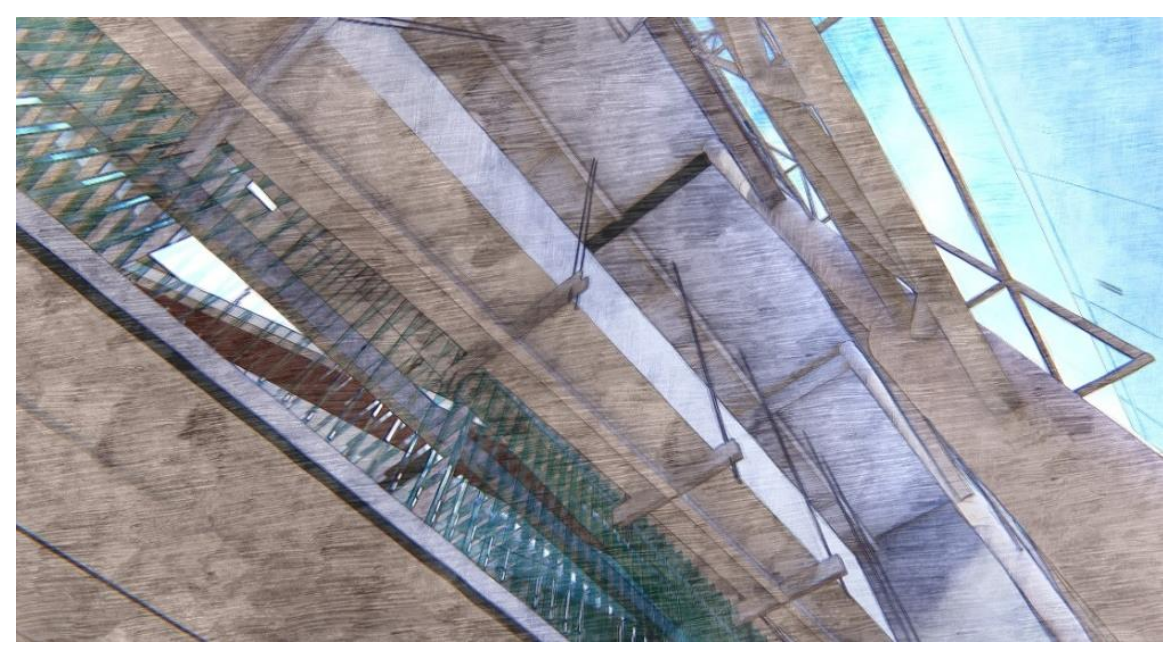

Gambar 5. Ruang kaca dan Struktur Ekspos

Sumber: Penulis, 2019

Denah museum secara harafiah dibuat unik agar arahan yang tercipta ini menggambarkan kondisi kerumitan atau susunan kota yang terjadi di Jakarta. Tatananya yang selalu berubah merupakan kesan yang ingin di tonjolkan bahwa nyatanya kota Jakarta saat ini masih tumpang tindih. Kerangka kaca pada ruang pameran merupakan bagian daripameran keringkihan gedung gedung bertingkat di Jakarta. Susunanya yang menjulang tinggi sebenearnya juga terpengaruh dari sifat-sifat yang menghuninya. Individualis dan ringkih bermaksud bahwa orang perkotaan terkadang telalu individualis dan mudah retak (stress).

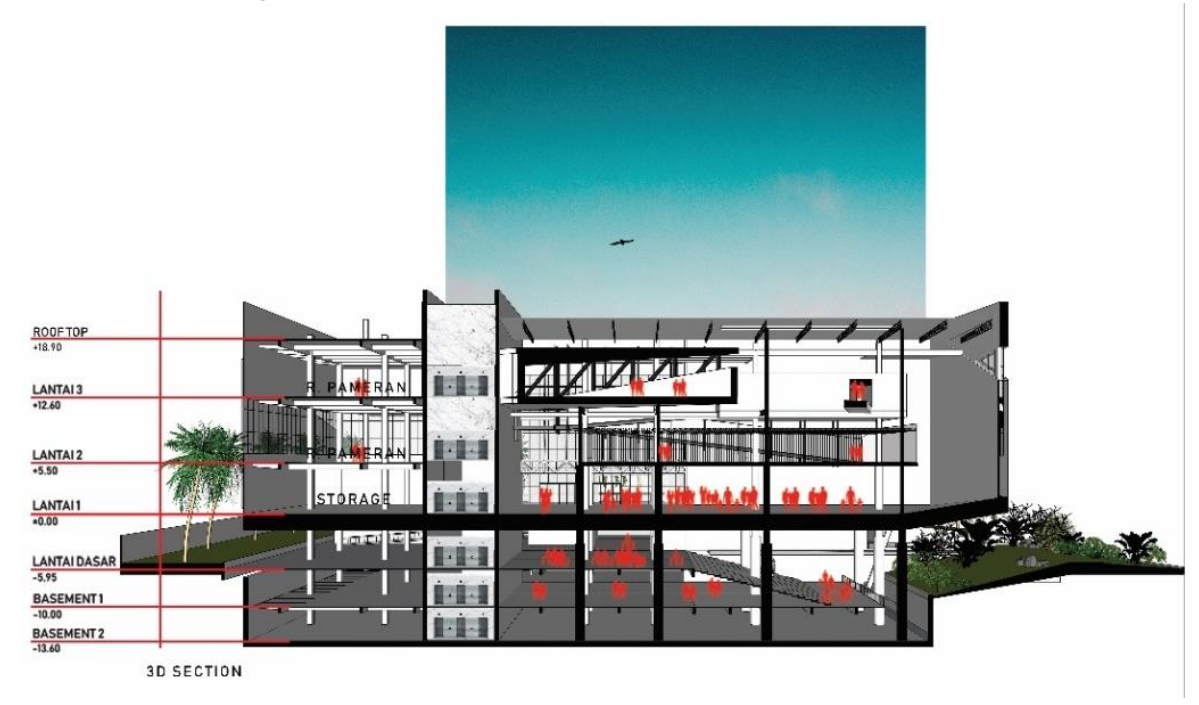

Gambar 4. Potongan 3D Museum

Sumber: Penulis, 2019

Desain juga mempertimbangkandan menjawab tantangan bagaimana bangunan ini mampu bertahan pada iklim tropis lembab Indonesia. Sehingga dapat di pastikan nantinya bangunan ini mampu berjalan dengan konsumsi energi yang dapat di minimalisir. Shaf ducting $A / C$ dan Hydrant di letakan di sekeliling bangunan. Melalui pengetahuan fisika dasar bahwa udara dingin cenderung memiliki massa jenis lebih berat daripada udara panas, maka dengan meletakan air flow di bagian ketinggian manusia udara dingin tersebut tidak akan terbuang cuma-cuma untuk mendinginkan udara panas. 

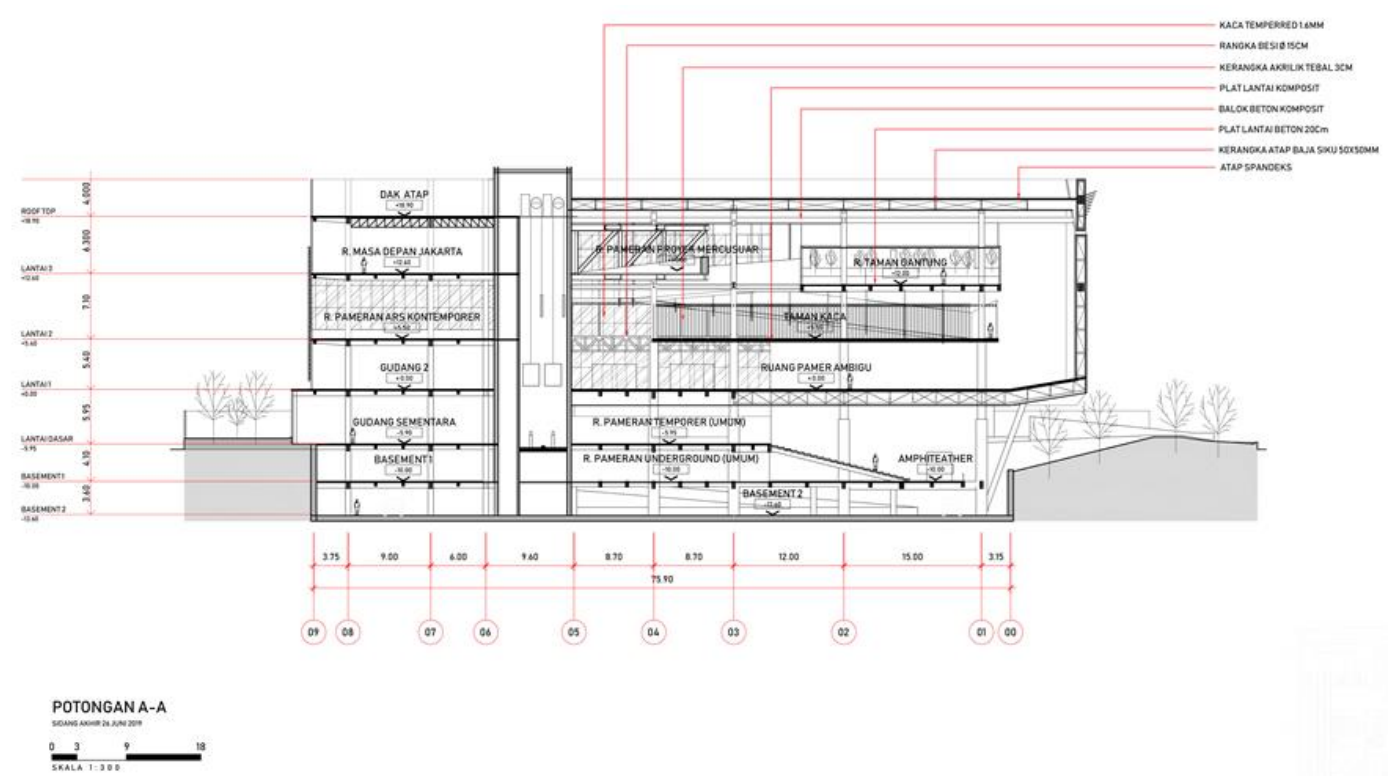

Gambar 7. Potongan Museum Arsitektur Jakarta

Sumber: Penulis, 2019

Sehingga, udara panas akan tetap ada dan berkumpul di bagian atas yang tidak di jangkau manusia. Dan udara dingin yang ada tidak berusaha mendinginkan udara panas tersebut. Ducting ac di letakan di bagian belakang bangunan. Untuk membungkus outdoor $A / C$ dinding pembatas dak atap ditinggikan sebanyak tiga meter. Selain bertujuan untuk alasan keamanan, dinding ini juga mampu membungkus mesin mesin operasional Museum. Rongga yang tercipta diharapkan juga mampu menampung panas radiasi matahari, sehingga lapisan pertama yang panas dan lapisan kedua yang berada di dalam interior tidak sepanas yang berada di bawah paparan matahari secara langsung.

Sedangkan pada bagian belakang bangunan merupakan pameran dengan sistem konvensional, dimana bagian belakang menjadi backbone atau penunjang cerita cerita yang ada di bagian ruang pameran lainnya. Ide desain yang dibuat kaku, lurus merupakan salah satu cara agar dalam penempatan pameran atau dalam proses pembangunannya lebih sistematis, mudah, terukur dan sederhana. 

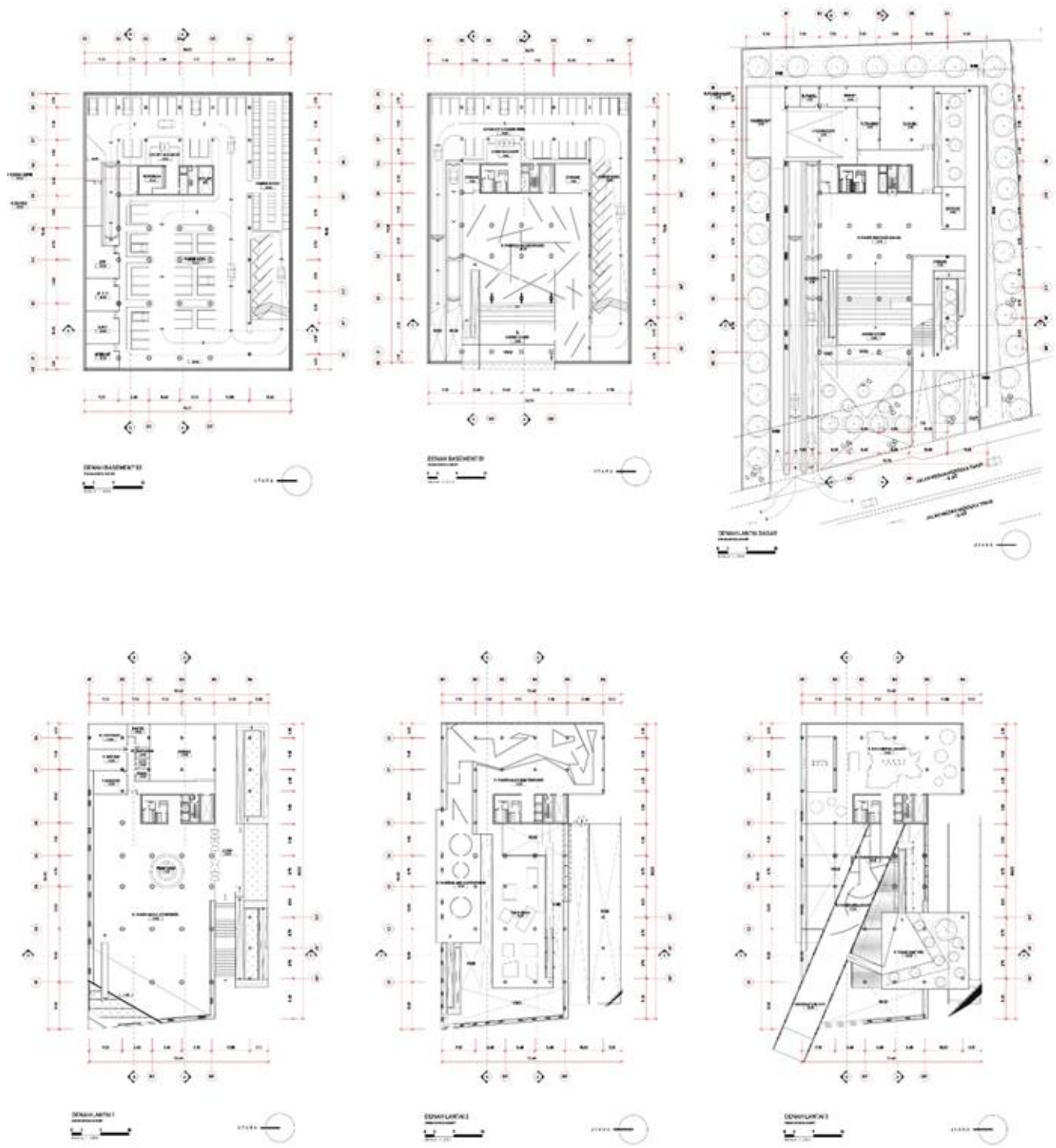

Gambar 6. Denah Museum Arsitektur Jakarta

Sumber: Penulis, 2019

Sifat lurus lurus juga bagian dari pemanfaatan ruang secara maksimal. Ruang belakang yang memiliki struktur dan tatanan konvensional bercerita dengan pameran tetap yang mempermainkan visual dan minim cahaya. Ruang tersebut kemudian diberikan sekat-sekat untuk membatasi ruang pameran, sekaligus untuk mengarahkan alur cerita Lingkup bagian tapak dikelilingi oleh KDH untuk pemenuhan standar resapan air hujan, dimana juga berfungsi sebagai jalur inspeksi darurat dan median evakuasi darurat. Begitupula dengan adanya jarak antar bangunan, menciptakan sebuah ruang ruang kosong untuk pertukaran udara pada amphiteater di bawah museum.

\section{Struktur}

Museum Arsitektur Jakarta dibangun dengan sistem struktur campuran, museum ini menggunakan sistem struktur plat dan kolom komposit, struktur diagrid dan struktur baja. Penggunaan baja komposit dimulai dari basement hingga lantai dua, baja wf yang digabung membentuk huruf $(+)$ kemudian di cor dengan beton. Tujuan digunakan baja salib atau plus sebenarnya untuk menopang berat beban pameran dan momen lendutan ke 4 sisi, sehingga lebih stabil. Baja wf ini kemudian di teruskan meuju jembatan cantilever. Sambungan baja 
dilanjutkan agar bagian atas bangunan menjadi ringan dan lebih fleksibel pada momennya. untuk dapat menopang cantilever bangunan di lantai 1 digunakan pula baja sistem cremona untuk membagi arah gaya tarik dan dorong pada bangunan.

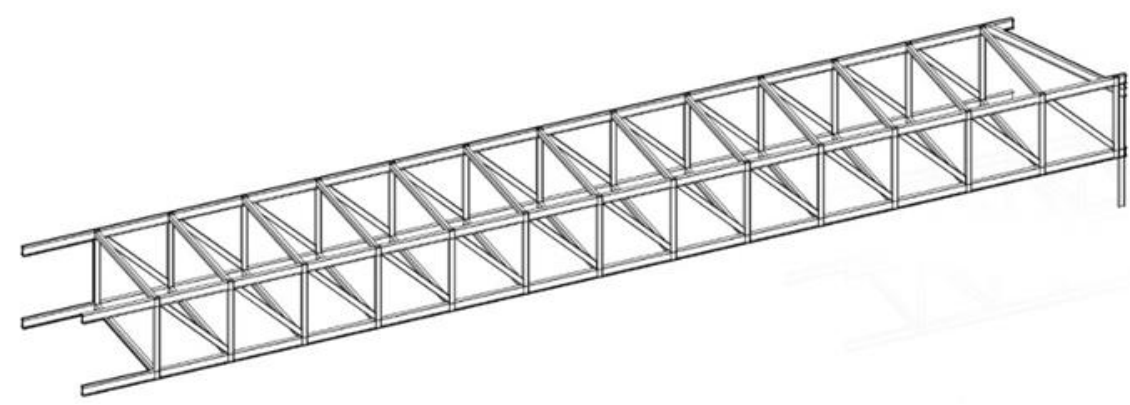

Gambar 9. Jembatan cantilever dengan struktur baja tarik. Sumber: Penulis, 2019

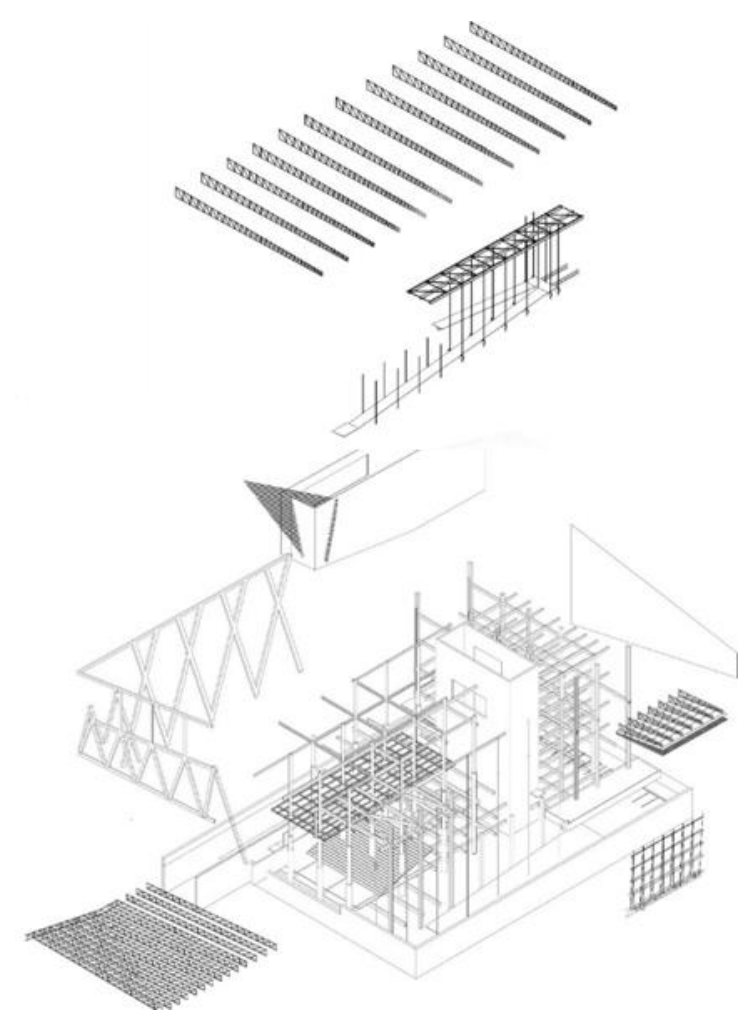

Gambar 10. Axonometri struktur Sumber: Penulis, 2019

Kemudian cantilever ini harus terbagi bebannya ke arah kiri maupun kanan yang bertujuan sebagai tumpuan utama untuk menopang beban mati. Untuk membagi beban di bagian kiri bangunan digunakanlah sistem diagrid dengan sudut kemiringan kolom $60^{\circ}$. Penggunaan diagrid sebesar $60^{\circ}$ ini merupakan alternatif sekaligus menjadi sebuah pameran langsung tentang struktur arsitektur. 


\section{KESIMPULAN DAN SARAN}

Perkembangan Jakarta sebagai tuntutan modernitas tidak diimbangi dengan Perkembangan museum sebagai jalur pariwisata. Padahal nilai historis kota Jakarta masih banyak yang dapat di gali dan diambil untuk kemudian dapat di ceritakan kepada turis. Pembangunan Jakarta juga harus berbenah, agar kota Jakarta mampu menjadi lebih baik dalam penataan kotanya yang masih di nilai tumpang tindih. Proyek ini juga diharapkan mampu menjadi contoh bagaimana mendesain sebuah banguan yang merespon iklim ataupin lingkungannnya. Bangunan yang merespon iklim tropis tidak melulu harus beratap miring, namun bisa juga dengan langkahlangkah yang tepat dalam merespon lingkungannnya. Pengambangan kota Jakarta juga harusnya di imbangi dengan peraturan yang relevan, agar tidak salah langkah dalam peremajaannya. Membangun sebuah kota yang sudah berusia hampir 500 tahun tidaklah mudah. Pembangunan sektor pariwisata juga harus di giatkan, agar pariwisata DKI Jakarta, dan perkembangan Museum menjadi lebih maksimal.

\section{REFERENSI}

Satiri T. (2018). Proyek Mercusuar Soekarno Untuk Asian Games IV Tahun 1962 Di Jakarta Wiedhana, D. (2017). Selamat Datang di Jakarta, Kota yang Dikepung Mal.

Zahnd, M. (1999). Perancangan Kota secara Terpadu, Yogyakarta: Kanisius, pp 107-110.

https://newsplus.antvklik.com/sports/proyek-mercusuar-soekarno-untuk-asian-games-ivtahun-1962-di-Jakarta

https://tirto.id/sarinah-proyek-mercusuar-sukarno-cmmV

https://tirto.id/selamat-datang-di-Jakarta-kota-yang-dikepung-mal-cmmR 
